\title{
Variation in the PPAR $\alpha$ gene is associated with altered function in vitro and plasma lipid concentrations in Type II diabetic subjects
}

\author{
D.M. Flavell ${ }^{1}$, I.Pineda Torra ${ }^{2}$, Y.Jamshidi ${ }^{1}$, D. Evans ${ }^{3}$, J. R. Diamond ${ }^{4}$, R. S. Elkeles ${ }^{4}$, S. R. Bujac ${ }^{5}$, G. Miller ${ }^{5}$, \\ P.J.Talmud ${ }^{1}$, B.Staels ${ }^{2}$, S. E.Humphries ${ }^{1}$ \\ ${ }^{1}$ Centre for Cardiovascular Genetics, Department of Medicine, Royal Free and University College London Medical School, \\ The Rayne Institute, London, UK \\ ${ }^{2}$ Department of Atherosclerosis, The Lille Pasteur Institute, U.325 INSERM and Faculty of Pharmacy, University of Lille II, \\ Lille, France \\ ${ }^{3}$ Medical Clinic, University hospital of Eppendorf, Hamburg, Germany \\ ${ }^{4}$ Department of Epidemiology and Public Health and Unit for Metabolic Medicine, Imperial College School of Medicine at \\ St Mary's Hospital, London, UK \\ ${ }^{5}$ MRC Epidemiology and Medical Care Unit, Wolfson Institute of Preventive Medicine, The Medical College of St Bartholomew's \\ Hospital, London, UK
}

\begin{abstract}
Aims/hypothesis. Peroxisome proliferator activated receptor alpha (PPAR $\alpha$ ) regulates genes involved in lipid metabolism, haemostasis and inflammation, in response to fatty acids and fibrates, making it a candidate gene for risk of dyslipidaemia, atherosclerosis and coronary artery disease. Plasma non-esterified fatty acids are increased in subjects with Type II (non-insulin-dependent) diabetes mellitus, suggesting that PPAR $\alpha$ could link Type II diabetes and dyslipidaemia, and affect response to fibrates. This has been investigated in association studies in healthy and diabetic subjects and in vitro studies.

Methods. The human PPAR $\alpha$ gene was isolated and screened for variation by single strand conformation polymorphism analysis. Genotypes were determined for 129 Type II diabetic subjects and 2508 healthy men. The association with plasma lipid concentrations was examined. The function of the V162 variant was examined in co-transfection assays.
\end{abstract}

Results. We identified two polymorphisms, one in intron 3 and a missense mutation, leucine 162 to valine, in the DNA binding domain. In Type II diabetic patients, V162 allele carriers had higher total cholesterol, HDL cholesterol and apoAI whereas intron 3 rare allele carriers had higher apoAI concentrations. By contrast, no effect was observed in healthy rare allele carriers. In vitro, the V162 variant showed greater transactivation of a reporter gene construct.

Conclusion/interpretation. Naturally occurring variation alters PPAR $\alpha$ function, influencing plasma lipid concentrations in Type II diabetic patients but not healthy people. This demonstrates that PPAR $\alpha$ is a link between diabetes and dyslipidaemia, and so could influence the risk of coronary artery disease, the greatest cause of morbidity and mortality in Type II diabetes. [Diabetologia (2000) 43: 673-680]

Keywords Polymorphism, Type II diabetes, nuclear receptors, $\operatorname{PPAR} \alpha$, dyslipidaemia.
Received: 25 November 1999 and in revised form: 27 January 2000

Corresponding author: Dr D. Flavell, Centre for Cardiovascular Genetics, Department of Medicine, University College London Medical School, The Rayne Institute, 5 University Street, London WC1E 6JJ, UK, D.M. Flavell, I. Pineda Torra contributed equally to the manuscript.

Abbreviations: CAD, coronary artery disease; HDL-C, HDL cholesterol; LDL-C, LDL cholesterol; NPHS2, The Second Northwick Park Heart Study, PPAR $\alpha$, peroxisome proliferator-activated receptor alpha; PPRE, peroxisome proliferator response element; SENDCAP, St. Mary's, Ealing, Northwick Park Diabetes Cardiovascular Disease Prevention Study; SSCP, single strand conformational polymorphism.
Risk of coronary artery disease (CAD) is determined by a combination of genetic and environmental factors which influence plasma lipid homeostasis, haemostasis and inflammation. Peroxisome proliferator activated receptor alpha (PPAR $\alpha)$ is a ligand-inducible transcription factor [1] which regulates the expression of genes involved in fatty acid oxidation, extracellular lipid metabolism, haemostasis [2] and inflammation [3]. Ligands for PPAR $\alpha$ include long chain fatty acids, eicosanoids, peroxisome proliferators, non-steroidal anti-inflammatory drugs and the fibrate class of hypolipidaemic drugs [4-6]. PPAR $\alpha$ is highly expressed in tissues with a high rate of fatty 
acid oxidation, particularly liver, kidney, skeletal muscle and heart and has a lower expression in other tissues [7] including smooth muscle cells [8], endothelial cells [9] and macrophage [10].

Fibrates are used in the treatment of dyslipidaemia and cause a reduction in plasma triglycerides, total cholesterol and LDL-cholesterol (LDL-C) and an increase in HDL-cholesterol (HDL-C) [2]. This produces a less atherogenic lipid profile and fibrates reduce the progression of atherosclerosis [11] and the incidence of CAD in clinical trials $[12,13]$. Diabetic dyslipidaemia is characterised by hypertriglyceridaemia and low HDL concentrations [14], for which fibrates are an effective therapy. Type II (non-insulin-dependent) diabetes mellitus is associated with increased mortality, primarily due to CAD [15] and fibrates reduce the incidence of CAD in Type II diabetic subjects [16]. Knockout of the mouse PPAR $\alpha$ gene results in abolition of the fibrate response [17], hyperlipidaemia [18] and sexually dimorphic steatosis and obesity in older animals [19]. Animals deficient in PPAR $\alpha$ cannot induce expression of hepatic $C Y P 4 A$ genes in response to diabetes and starvation [20] and die of severe hypoglycaemia upon pharmacological blocking of fatty acid oxidation [21]. Therefore PPAR $\alpha$ is a key metabolic regulator involved in the regulation of lipid and glucose homeostasis. It modulates the expression of many genes and so a minor alteration in function could have a pronounced effect, particularly in a pathophysiological situation such as Type II diabetes in which non-esterified fatty acid (NEFA) concentrations are raised [22]. The purpose of this study was to identify variation in the human PPAR $\alpha$ gene and to determine the association between variants and plasma lipid concentrations in Type II diabetic and healthy subjects.

\section{Materials and methods}

Study samples. We screened for variation by SSCP in 48 healthy Caucasian men from the Second Northwick Park Heart Study (NPHS2) [23]. Polymorphisms were genotyped in 2508 participants in NPHS2, a prospective study of coronary artery disease in middle-aged (50-61 year-old) healthy men [23] and 129 Type II diabetic men and women (86 European, 43 Asian) from the St. Mary's, Ealing, Northwick Park Diabetes Cardiovascular Disease Prevention (SENDCAP) Study, a doubleblind placebo-controlled study of the effect of bezafibrate treatment on plasma lipid concentrations and cardiovascular outcomes in Type II diabetes [16]. Exclusion criteria for NPHS2 included a history of Type II diabetes, unstable angina or previous myocardial infarction or stroke [23]. Inclusion criteria for the SENDCAP study included no history of CAD, age between 33 and 65 years and any of the following in a screening sample: total cholesterol $5.2 \mathrm{mmol} / \mathrm{l}$ or more, triglyceride $1.8 \mathrm{mmol} / \mathrm{l}$ or more, HDL $1.1 \mathrm{mmol} / \mathrm{l}$ or less and total cholesterol:HDL 4.7 or more. Exclusion criteria included total cholesterol or triglyceride more than $8 \mathrm{mmol} / \mathrm{l}$, total cholesterol:HDL more than 7.2, severe hypertension, severe carotid stenosis and hypolipidaemic or anticoagulant therapy [16].
Table 1. Intron exon boundaries in the human $P P A R \alpha$ gene

\begin{tabular}{llll}
\hline Exon & Donor & Acceptor & Exon \\
\hline 1 & CACAG gtaaa & cacag TTCTG & 2 \\
2 & AAGAG gtaca & cccag TAGCT & 3 \\
3 & CACGG gtaag & cccag ACACG & 4 \\
4 & GCAAG gtaga & cacag GGCTT & 5 \\
5 & CAACG gtagg & cctag CGATT & 6 \\
6 & ATCCA gtagg & tgtag CCTTT & 7 \\
7 & TGGAG gtgag & actag ATCGT & 8 \\
\hline
\end{tabular}

Nucleotides in uppercase letters correspond to exon sequence and nucleotides in lowercase letters correspond to intronic sequence

Structure of the human PPAR $\alpha$ gene. Intron-exon boundaries (Table 1) were obtained by sequencing a bacterial artificial chromosome (BAC) clone containing the human PPAR $\alpha$ gene (kind gift of B. Wilkinson; Glaxo Wellcome, Research Triangle Park, N.C., USA).

Identification of polymorphisms. Polymerase chain reaction primer pairs (Table 2) were designed for the eight coding exons of the human PPAR $\alpha$ gene (conditions available on request). The PPAR $\alpha$ genomic sequence has since been released on Genbank, accession numbers Z94161, AL032818 and AL078611. Single strand conformational polymorphism (SSCP) analysis was done as described previously [24]. Samples were sequenced using the dRhodamine terminator cycle sequencing kit on an ABI PRISM 377 DNA sequencer (Perkin-Elmer, La Jolla, Calif., USA).

Genotype determination. Restriction enzyme digestion assays were designed for the polymorphisms. The intron 3 polymorphism creates an MaeII site but the $L 162 \mathrm{~V}$ polymorphism does not alter a restriction enzyme site, therefore a forced-site assay was used. Polymerase chain reaction reactions were done in $20 \mu \mathrm{l}$, containing $1 \times \mathrm{NH}_{3}$ buffer $\left(16 \mathrm{mmol} / 1 \quad\left[\mathrm{NH}_{4}\right]_{2} \mathrm{SO}_{4}: 67\right.$ $\mathrm{mmol} / \mathrm{l}$ TRIS $\mathrm{pH}$ 8.4:0.01\% Tween 20:0.02 mmol/1 each deoxyribonucleoside triphosphate), $80 \mathrm{mmol} / 1 \mathrm{MgCl}_{2}, 8.3 \mathrm{pmol}$ each primer, 0.2 units $\mathrm{Taq}$ polymerase. Polymerase chain reaction reactions were digested and analysed using the microtitre array diagonal gel electrophoresis (MADGE) system [25].

Statistical analysis. Genotype information was analysed using the SPSS 6.1 statistical package (Chicago, Ill., USA). Allele frequencies were determined by the gene counting method and compared using the chi-squared test. Distribution of variables were checked and log transformed where necessary. For the SENDCAP study, means of baseline plasma lipid concentrations between Europeans and Asians were compared by independent samples $t$ test. The effect of PPAR $\alpha$ genotype on baseline and on treatment plasma lipid concentrations was examined by ANOVA using genotype as a factor and age, BMI, sex and smoking as covariates. The effect of genotype in the bezafibrate-treated group was determined by ANOVA with genotype as a factor. For the NPHS2 study, BMI and smoking were used as covariates. A value of $p 0.05$ or less was considered significant.

Plasmid construction. The V162-PPAR $\alpha$ expression plasmid was derived from the pSG5-hPPAR $\alpha$ vector containing a full length $P P A R \alpha$ cDNA [8]. The $\mathrm{C} \rightarrow \mathrm{G}$ change was introduced using the QuikChange site-directed mutagenesis kit (Stratagene, La Jolla, Calif., USA) with oligonucleotide 5 '-CGATTTCACAAGTGCGTTTCTGTCGGGATG-3' and its com- 


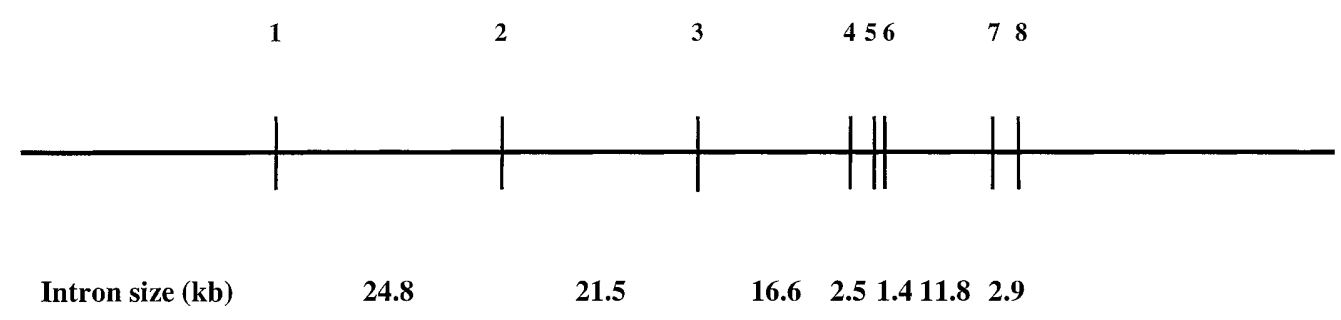

$10 \mathrm{~kb}$

Fig. 1. Intron-exon structure of the human $P P A R \alpha$ gene

plementary strand. The PPRE $\times 6$-TKpGL3 reporter construct containing 6 copies of a peroxisome proliferator response element (PPRE) was generated by PCR using plasmid J3TKpGL3 [26] and oligonucleotides 5'-ACGTGTCGACACTAGTGGCTAGAGGATCTCTACCAGG-3' and 5'-CGATGGTACCCTCGAGCAATGTGCTAGCGAGATCCTTCAACCTTTACC-3'. The PCR product was digested with KpnI and SpeI and cloned into FTKpGL3 plasmid digested with KpnI and NheI. Sequence was confirmed using an ABI PRISM 377 automatic sequencer (Perkin Elmer).

Transfection assays and western blot analysis. We transfected HepG2 cells using the cationic lipid RPR 120535B (Rhone Poulenc Rorer, Vitry, France) with a mixture of plasmids containing $10 \mathrm{ng}$ of the firefly luciferase reporter plasmid driven by six copies of a PPRE (PPRE $\times 6$-TKpGL3), $30 \mathrm{ng}$ of the pSG5-hPPAR $\alpha$ expression vectors (L162- or V162-) and $2 \mathrm{ng}$ of the Renilla luciferase reporter plasmid, pRL-SV40, as the internal control (Promega, Madison, Wis., USA). When $P P A R \alpha$ plasmid was not co-transfected, pSG5 vector (Strategene, La Jolla, Calif., USA) was added to the transfection mixture. Samples were made up to $500 \mathrm{ng}$ with pBSKS plasmid (Stratagene). After $2 \mathrm{~h}$ cells were incubated with Wy14,643 or vehicle (dimethyl sulphoxide) in medium containing $2 \%$ Ultroser (Biosepra, Marlboro, Mass., USA). Luciferase activity was assayed $36 \mathrm{~h}$ later using the Dual-Luciferase reporter assay system (Promega). Results were expressed in relative light units (RLU). Cells were transfected in sextuplicate, three samples were used for the luciferase assay and three samples were analysed for hPPAR $\alpha$ protein concentrations using a hPPAR $\alpha$ specific antibody as described [10].

\section{Results}

The structure of the $P P A R \alpha$ gene was determined by comparing the sequence of the human PPAR $\alpha$ cDNA [27] and the sequence obtained from a bacterial artificial chromosome (BAC) clone containing the human PPAR $\alpha$ gene. The human PPAR $\alpha$ gene spans at least $88.5 \mathrm{~kb}$ of genomic DNA (Fig. 1). As in the mouse gene, the human gene contains at least eight exons in which exon 1,2 and the $5^{\prime}$ end of exon 3 and $3^{\prime}$ end of exon 8 are not translated. The $3^{\prime}$ untranslated region could be very large as the PPAR $\alpha$ mRNA is approximately $10 \mathrm{~kb}$ [28] and there are multiple expressed sequence tag matches to the region $3^{\prime}$ of exon 8 . Intron positions are conserved between human and mouse and the splice acceptor and donor sites followed the gt/ag rule and were very similar to the mouse gene [29] (Table 1).

All coding exons of the human PPAR $\alpha$ gene were screened by SSCP in 48 British men and variant patterns were seen in two fragments. Sequencing of the exon 2 variant showed a $\mathrm{G}$ to $\mathrm{A}$ transversion $11 \mathrm{bp}$ into intron 3 (intron $3 \mathrm{G} / \mathrm{A}$ ) at nucleotide 2176 of Genbank sequence AL032818 (sequence reversed). The exon 5 variant is a $\mathrm{G}$ to $\mathrm{C}$ transversion at the first

Table 2. PCR primers

\begin{tabular}{llll}
\hline Exon & Forward Primer & Reverse Primer & Product (bp) \\
\hline 2 & GTCCATTCAAGCTGCTATAA & AGTGCTCGAAGGATCACCTA & 230 \\
$35^{\prime}$ & CCAATGGTTCCTCTTTCTC & CTTCCAGAACTATCCTCGCC & 209 \\
$33^{\prime}$ & CTCGGCGGCACAACAGCA & CGGCACACTTACCCGTGATGAC & 251 \\
4 & ACGGGATAGTGATGCCTGGA & AAGTAGTTGATGGTGGCGGC & 258 \\
5 & AGATCCACTGTGTATTACC & GAAAATGTGGAGGGCCACCT & 193 \\
6 & GCCTGTGTTTCCCCCTCCAA & AACCCAGAACAGCCGCAAAC & 255 \\
$75^{\prime}$ & CCTTGGTGTCCTCCTTTG & GTTTGCGAAGCCTGGGAT & 207 \\
7 & ACCGTCACGGAGCTCACGGA & CTTGGGTTCCATGATATCAC & 227 \\
$73^{\prime}$ & TATTCGCCATGCTGTCTTCT & GTGACGTGATACCGGCAGAT & 246 \\
$85^{\prime}$ & AACCTCTCTCTCTTCTTTCG & ACTCCGTCTTCTTGATGAT & 222 \\
8 & CTGGTGACGGAGCATGCGCA & CTACAGCTCAGACTGTCCAA & 235 \\
$83^{\prime}$ & CAGGAGTTCTGAAGCTGACA & CTTCCCAGTCCTGAGATTAG & 204 \\
Intron 3 & Exon 2 forward & AGGAAGACACGATGCTCCTAC & 189 \\
L $162 \mathrm{~V}$ & Exon 5 forward & GTGACATCCCGACAGAAG & 158 \\
\hline
\end{tabular}


Table 3. Allele frequencies of $P P A R \alpha$ polymorphisms

\begin{tabular}{llll}
\hline$n$ & $\begin{array}{l}\text { Type II diabetic } \\
\text { Europeans (83) }\end{array}$ & $\begin{array}{l}\text { Type II diabetic } \\
\text { Asian (40) }\end{array}$ & $\begin{array}{l}\text { Healthy } \\
\text { European } \\
(2508)\end{array}$ \\
\hline Intron 3 & 0.064 & 0.037 & 0.086 \\
& $(0.03-0.10)$ & $(0-0.08)$ & $(0.08-0.09)$ \\
L162V & 0.066 & 0.025 & 0.062 \\
& $(0.03-0.10)$ & $(-0.01-0.06)$ & $(0.05-0.07)$ \\
\hline
\end{tabular}

(95\% confidence intervals)

base of codon 162 (nt 309 of reverse of Genbank sequence AL078611), creating a missense mutation which alters leucine to valine $(L 162 \mathrm{~V})$. Genotypes of the intron 3 and $L 162 \mathrm{~V}$ polymorphisms were determined for 129 European and Asian Type II diabetic subjects participating in the SENDCAP study [16]. The frequency of the intron $3 A$ allele was 0.064 (95\% CI 0.03-0.10) in Europeans and 0.037 (95\% CI 0-0.08) in Asians whereas the V162 allele frequency was 0.066 (95\% CI 0.03-0.10) in Europeans and 0.025 (95\% CI 0-0.06) in Asians (Table 2). Rare allele frequencies were not different between Type II diabetic Europeans and Asians (intron $3 \chi^{2}=0.78$, L162V $\chi^{2}=1.82$ ). No homozygotes for either rare allele were detected in the SENDCAP sample and genotype distribution was not different from expected Hardy-Weinberg proportions.
Genotypes were determined for 2508 healthy middle-aged men participating in the NPHSII study. Genotype distributions were in Hardy-Weinberg proportions. The allele frequency for the intron $3 \mathrm{~A}$ allele was 0.086 (95\% CI 0.08-0.09) and for the V162 allele 0.062 (95\% CI 0.05-0.07) (Table 3). The intron 3 and $L 162 \mathrm{~V}$ polymorphisms were not in linkage disequilibrium (Delta $=0.01, p=1.0)$. Allele frequencies were not statistically significantly different between the NPHS2 and SENDCAP studies.

Association between the PPAR $\alpha$ variants and baseline plasma lipid concentration in European and Asian Type II diabetic subjects was examined (Table 4). Duration of diabetes, treatment (hypertension and oral glycaemic) and race did not affect the statistical significance levels of the results. Mean baseline plasma lipid concentrations were not different between Europeans and Asians and the PPAR $\alpha$ genotypes showed effects of similar magnitude in both ethnic groups and so these ethnic groups were combined. Intron $3 A$ allele carriers had $11 \%$ higher HDL-C $(p=0.06), 32 \%$ higher $\mathrm{HDL}_{2}$ cholesterol $(p=0.08)$ and $16 \%$ higher apoAI $(p=0.002)$ concentrations whereas total cholesterol:HDL-C ratio was $13 \%$ lower in $A$ allele carriers than $G$ allele homozygotes $(p=0.03)$. Carriers of the $V 162$ allele had $9 \%$ higher plasma total cholesterol $(p=0.04)$ and non-HDL-C $(p=0.07)$ than $L 162$ allele homozygotes. Concentrations of HDL-C were $10 \%$ higher $(p=0.05), \mathrm{HDL}_{2}$ cholesterol $31 \%$ higher

Table 4. Effect of PPAR $\alpha$ polymorphisms on baseline plasma lipid concentrations in the SENDCAP study

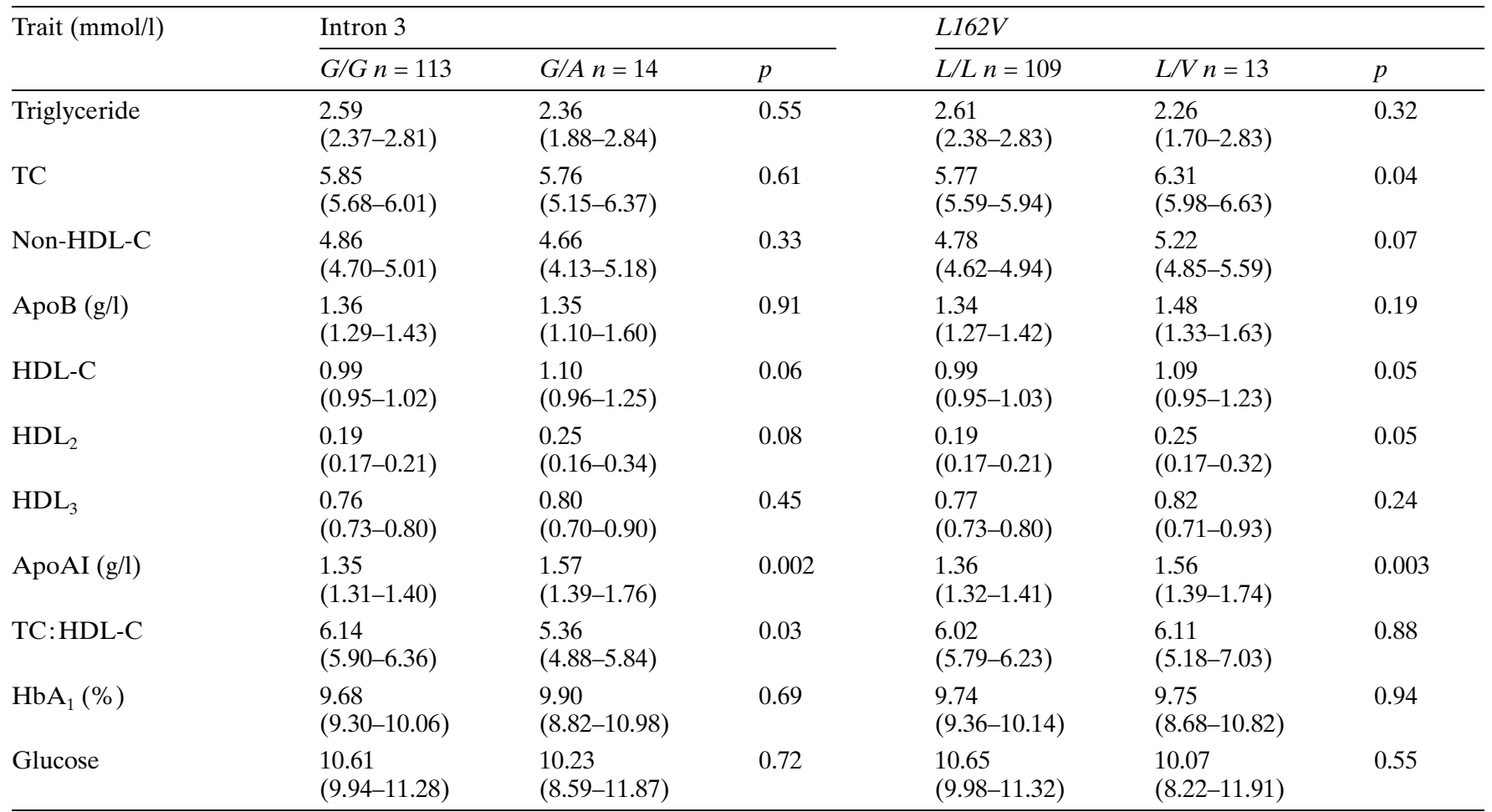

Values are means $(95 \% \mathrm{CI})$ of individual median pretreatment measures. All values are mmol/l except where indicated. TC $=$ total cholesterol 
Table 5. Effect of $P P A R \alpha$ polymorphisms on plasmid lipid measures in healthy middle-aged men

\begin{tabular}{|c|c|c|c|c|c|c|}
\hline \multirow[t]{2}{*}{ Trait } & \multicolumn{3}{|l|}{ Intron 3} & \multicolumn{3}{|l|}{$L 162 \mathrm{~V}$} \\
\hline & $\begin{array}{l}G / G+G / A \\
(n=2487)\end{array}$ & $\begin{array}{l}A / A \\
(n=16)\end{array}$ & $p$ & $\begin{array}{l}L / L+L / V \\
(n=2500)\end{array}$ & $\begin{array}{l}V / V \\
(n=8)\end{array}$ & $p$ \\
\hline Cholesterol & $\begin{array}{l}5.74 \\
(5.70-5.78)\end{array}$ & $\begin{array}{l}5.64 \\
(5.15-6.13)\end{array}$ & 0.70 & $\begin{array}{l}5.73 \\
(5.69-5.77)\end{array}$ & $\begin{array}{l}5.79 \\
(5.09-6.48)\end{array}$ & 0.88 \\
\hline apoB & $\begin{array}{l}0.87 \\
(0.86-0.88)\end{array}$ & $\begin{array}{l}0.78 \\
(0.67-0.91)\end{array}$ & 0.15 & $\begin{array}{l}0.87 \\
(0.86-0.88)\end{array}$ & $\begin{array}{l}0.95 \\
(0.75-1.21)\end{array}$ & 0.46 \\
\hline apoAI & $\begin{array}{l}1.62 \\
(1.60-1.53)\end{array}$ & $\begin{array}{l}1.73 \\
(1.56-1.91)\end{array}$ & 0.19 & $\begin{array}{l}1.62 \\
(1.60-1.63)\end{array}$ & $\begin{array}{l}1.56 \\
(1.29-1.83)\end{array}$ & 0.69 \\
\hline
\end{tabular}

Values are means $(95 \% \mathrm{CI})$ (geometric mean for triglyceride). ApoAI and apoB concentrations were only measured in a subset of the sample

Table 6. Effect of PPAR $\alpha$ polymorphisms on change in plasma lipids concentrations in bezafibrate-treated participants in the SENDCAP study

\begin{tabular}{|c|c|c|c|c|c|c|}
\hline \multirow[t]{2}{*}{ Trait (mmol/l) } & \multicolumn{3}{|l|}{ Intron 3} & \multicolumn{3}{|l|}{$L 162 \mathrm{~V}$} \\
\hline & $G / G n=53$ & $G / A n=9$ & $p$ & $L / L n=50$ & $L / V n=8$ & $p$ \\
\hline $\mathrm{TC}$ & $-0.42 \pm 0.08$ & $-0.71 \pm 0.29$ & 0.28 & $-0.42 \pm 0.09$ & $-0.90 \pm 0.22$ & 0.04 \\
\hline ApoB (g/l) & $+0.09 \pm 0.05$ & $-0.07 \pm 0.14$ & 0.29 & $+0.09 \pm 0.05$ & $-0.17 \pm 0.11$ & 0.15 \\
\hline HDL-C & $+0.09 \pm 0.02$ & $+0.11 \pm 0.03$ & 0.92 & $+0.07 \pm 0.02$ & $+0.12 \pm 0.06$ & 0.39 \\
\hline ApoAI (g/l) & $-0.02 \pm 0.03$ & $-0.16 \pm 0.11$ & 0.08 & $-0.03 \pm 0.03$ & $-0.15 \pm 0.07$ & 0.18 \\
\hline TC:HDL-C & $-0.75 \pm 0.15$ & $-0.96 \pm 0.35$ & 0.87 & $-0.72 \pm 0.15$ & $-1.29 \pm 0.31$ & 0.19 \\
\hline
\end{tabular}

Values are means \pm SEM of individual pretreatment median values subtracted from individual post-treatment median values. $\mathrm{TC}=$ total cholesterol

$(p=0.05)$ and apoAI $15 \%$ higher $(p=0.003)$ in V162 carriers compared with $L 162$ homozygotes. No effects on fasting glucose or glycated haemoglobin $\left(\mathrm{HbA}_{1}\right)$ were observed with either polymorphism (Table 4).

We also examined the association between the PPAR $\alpha$ polymorphisms and plasma total cholesterol, triglycerides, apoB and apoAI concentrations in the 2508 healthy NPHSII men. There were no statistically significant differences in plasma lipid concentrations between common allele homozygotes and heterozygotes. Homozygotes for the rare intron $3 \mathrm{~A}$ allele had $26 \%$ lower plasma triglycerides compared with common $G$ allele homozygotes and $G / A$ heterozygotes. No statistically significant differences in plasma lipid concentrations were observed for V162 homozygotes (Table 5).

We also examined the association between the $P P A R \alpha$ gene variants and response of plasma lipid traits to bezafibrate treatment in the SENDCAP study (Table 6). In the SENDCAP study, bezafibrate treatment caused a reduction in total cholesterol of $7.4 \%$, non-HDL-C of $12.3 \%$ and total cholesterol:HDL-C ratios of $12 \%$ and an increase in HDL-C of $6.4 \%$ over 3 years [16]. Bezafibrate treated V162 allele carriers showed a twofold greater lowering of total cholesterol $(-0.90$ vs $-0.42 \mathrm{mmol} / \mathrm{l}, p=0.04)$ and non-
HDL-C ( -1.01 vs $-0.50 \mathrm{mmol} / \mathrm{l}, p=0.04)$ than treated L162 allele homozygotes. There was no statistically significant effect of intron 3 genotype on change in plasma lipid concentrations on bezafibrate treatment.

Transient transfection assays in the HepG2 human hepatoma cell line were done to compare L162hPPAR $\alpha$ to V162-hPPAR $\alpha$ transcriptional activity. The V162-hPPAR $\alpha$ variant showed similar unstimulated (vehicle) basal transcriptional activity compared with L162-PPAR $\alpha$ on a synthetic promoter driven by multimerized copies of a PPRE. In the presence of the PPAR $\alpha$ ligand Wy14,643, V162PPAR $\alpha$ showed enhanced transactivation activity compared with L162-PPAR $\alpha$ (Fig. 2). This difference was not due to enhanced protein production by the V162-hPPAR $\alpha$ expression vector because protein concentrations of both variants were similar after transient transfection as assessed by western blot analysis (not shown).

\section{Discussion}

The coding region and intron-exon boundaries of the $P P A R \alpha$ gene were screened for variation and a missense mutation $(L 162 \mathrm{~V})$ and an intronic mutation (in- 


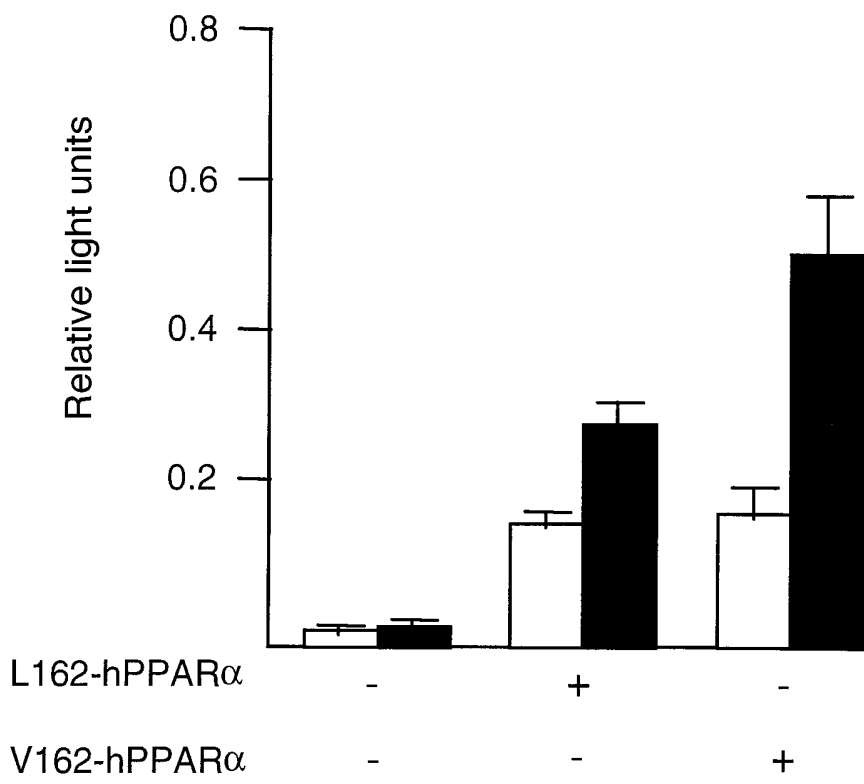

Fig. 2. The V162-PPAR $\alpha$ isoform has increased PPRE-dependent transcriptional activity compared with the L162-PPAR $\alpha$ isoform. HepG2 cells, transfected with a PPRE $\times 6$-TKpGL3 reporter and either the L162-hPPAR $\alpha$ or the V162-hPPAR $\alpha$ expression plasmids, were incubated in the presence of Wy14,643 (50 $\mu \mathrm{mol} / 1, \square)$ or vehicle (dimethyl sulphoxide, $\square$ ). Values (means \pm SD) represent firefly luciferase activity normalised relative to a Renilla luciferase transfection internal control. Three independent experiments were done with similar results

tron 3) were identified. Allele frequencies were not statistically significantly different between healthy Caucasians and Type II diabetic subjects, suggesting that they do not have a major causal role in Type II diabetes, although the SENDCAP study has limited power to detect modest effects.

In Type II diabetic subjects, the PPAR $\alpha$ polymorphisms exerted a dominant effect on apoAI concentrations in rare allele carriers. By contrast, the $P P A R \alpha$ polymorphisms have little effect on plasma lipids in healthy men, with no difference observed between common allele homozygotes and rare allele carriers and only intron 3 rare allele homozygotes showing an effect on plasma triglycerides. These data imply a homeostatic role for PPAR $\alpha$ in diabetic dyslipidaemia. We hypothesise that in the healthy state, when plasma lipids and NEFA are in the normal range, PPAR $\alpha$ activity is not limiting and so the polymorphisms, which presumably have slightly altered function, do not show an effect. In Type II diabetes, high plasma NEFA could activate PPAR $\alpha$, enhancing functional differences and explaining the 'dominant' effect observed. PPAR $\alpha$ gene expression [30] and transcriptional activity [31] are regulated by insulin. This study confirms that PPAR $\alpha$ is involved in diabetic dyslipidaemia.

The PPAR $\alpha$ alters plasma lipids concentrations by regulating the expression of genes involved in fatty acid oxidation and extracellular lipid metabolism [3]. In healthy men, intron 3 rare allele homozygotes had lower plasma triglyceride than common allele homozygotes and heterozygotes. In Type II diabetic subjects carriers of either rare allele showed a trend for lower triglyceride concentrations, which might not have reached significance due to high individual variability in plasma triglyceride concentration and low sample number. Fibrates lower plasma triglyceride by PPAR $\alpha$-mediated down regulation of apoCIII gene expression [32] and the PPAR $\alpha$ polymorphisms could alter regulation of the apoCIII gene, though plasma apoCIII concentrations were not determined in either study. In Type II diabetic subjects, carriers of either rare allele had significantly higher apoAI concentrations. The PPAR $\alpha$ regulates expression of the human apoAI [33-36] and apoAII genes [26] and so higher HDL measures could reflect up regulation of these genes. Additionally, V162 allele carriers had higher baseline total cholesterol and non-HDL-C, with a trend of similar magnitude for higher apoB concentrations. Fibrates lower plasma total cholesterol concentrations by lowering VLDL synthesis and increasing clearance of triglyceride-rich lipoproteins [2], although LDL-C rose in Type II diabetic subjects treated with gemfibrozil [37] and bezafibrate [38].

The effect of PPAR $\alpha$ polymorphisms on response to bezafibrate in the SENDCAP study was also examined. Bezafibrate-treated V162 allele carriers showed a greater lowering of total cholesterol and non-HDL-C than bezafibrate-treated $L 162$ allele homozygotes. The weak effect of the variants on response could be partly explained by the observation that bezafibrate is not PPAR $\alpha$ specific and also interacts with $\operatorname{PPAR} \beta / \delta$ and $\operatorname{PPAR} \gamma[6]$.

Cardiovascular disease is the major cause of morbidity and mortality in Type II diabetic subjects in western society [15] and dyslipidaemia is predictive of CAD events [39, 40] and mortality [41] in this condition. The Multiple Risk Factor Intervention Trial showed that risk attributable to increasing cholesterol was higher in diabetic than non-diabetic subjects [15] and the 4S study suggested a greater benefit of cholesterol lowering in Type II diabetic patients [42]. Both polymorphisms are associated with higher HDL-C, and intron 3 A allele carriers also have a lower total cholesterol:HDL-C ratio, both of which are strong predictors of cardiovascular mortality in Type II diabetic subjects [39, 40]. No frequency differences were observed for ischaemic events with either polymorphism, although the SENDCAP study does not have the power to detect modest effects.

The mechanisms underlying the effect of the $L 162 \mathrm{~V}$ variant have been investigated. In co-transfection experiments, V162-PPAR $\alpha$ showed similar basal transactivation of a PPRE-driven reporter gene compared with L162-PPAR $\alpha$. When treated with the PPAR $\alpha$ ligand Wy14,643, V162-PPAR $\alpha$ showed, 
Human/Mouse PPAR $\alpha$

Rat PPAR $\alpha$

Xenopus PPAR $\alpha$

Human/mouse/hamster PPAR $\gamma$

Xenopus PPAR $\gamma$

Human PPAR $\delta$

Mouse PPAR $\delta$

Rat $\operatorname{PPAR} \delta$

Xenopus PPAR $\beta$

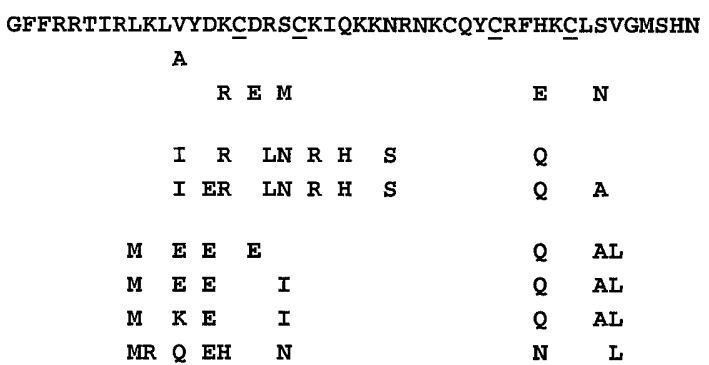

Fig.3. Alignment of sequences encoded by exon 5 of the PPAR gene subfamily. Leucine 162 of PPAR $\alpha$ is indicated by an asterisk. Cysteine residues coordinating the zinc atom of the second zinc finger are indicated by $\mathbf{C}$ however, approximately twofold greater transactivation than L162-PPAR $\alpha$. Exon 5 encodes the second zinc finger of the DNA binding domain and although leucine to valine is a conservative change, $\mathrm{L} 162 \mathrm{~V}$ is situated adjacent to a cysteine which coordinates the $\mathrm{Zn}^{2+}$ atom of the second zinc finger (Fig. 3) and immediately upstream of a region determining the specificity and polarity of PPAR $\alpha$ binding to different PPREs [43]. The L162V polymorphism could only differentially affect the PPREs in a subset of PPAR $\alpha$-regulated genes, as PPRE sequences vary in different genes [44]. The intron 3 polymorphism is situated $10 \mathrm{bp}$ into intron 3 , outside the consensus splice donor sequence, suggesting that it is not functional but is in allelic association with a variant in a regulatory region affecting $P P A R \alpha$ gene expression and hence PPAR $\alpha$ protein concentrations. This could explain the effects observed on HDL measures with both polymorphisms, whereas the effect on total cholesterol concentrations is only seen with the $\mathrm{L} 162 \mathrm{~V}$ polymorphism.

In conclusion, variation in the PPAR $\alpha$ gene affects dyslipidaemia in Type II diabetic subjects and so could alter their risk of CAD.

Acknowledgements. We thank the British Heart Foundation (BHF) for support for S.E. Humphries, P.J. Talmud (RG007) and Y. Jamshidi (FS/98058). This work is also supported by Biomed 2 Concerted Action Grant PL 963324. The SENDCAP study was supported by the BHF and Boehringer-Mannheim. I. Pineda Torra is supported by European grant ERBFMBICT983214 and B. Staels is supported by ARCOL (the French committee for the coordination of research on atherosclerosis and cholesterol). We acknowledge E. Leitersdorf for helpful discussion.

\section{References}

1. Dreyer C, Krey G, Keller H, Givel F, Helftenbein G, Wahli W (1992) Control of the peroxisomal beta-oxidation pathway by a novel family of nuclear hormone receptors. Cell 68: 879-887

2. Schonfeld G (1994) The effects of fibrates on lipoprotein and hemostatic coronary risk factors. Atherosclerosis 111: 161-174

3. Fruchart J, Duriez P, Staels B (1999) Peroxisome proliferator-activated receptor-alpha activators regulate genes governing lipoprotein metabolism, vascular inflammation and atherosclerosis. Curr Opin Lipidol 10: 245-257
4. Devchand PR, Keller H, Peters JM, Vazquez M, Gonzalez FJ, Wahli W (1996) The PPARalpha-leukotriene B4 pathway to inflammation control. Nature 384: 39-43

5. Lehmann JM, Lenhard JM, Oliver BB, Ringold GM, Kliewer SA (1997) Peroxisome proliferator-activated receptors alpha and gamma are activated by indomethacin and other non-steroidal anti-inflammatory drugs. J Biol Chem 272: 3406-3410

6. Krey G, Braissant O, L'Horset F et al. (1997) Fatty acids, eicosanoids, and hypolipidemic agents identified as ligands of peroxisome proliferator-activated receptors by coactivator-dependent receptor ligand assay. Mol Endocrinol 11: 779-791

7. Braissant O, Foufelle F, Scotto C, Dauca M, Wahli W (1996) Differential expression of peroxisome proliferatoractivated receptors (PPARs): tissue distribution of PPARalpha, -beta, and -gamma in the adult rat. Endocrinology 137: 354-366

8. Staels B, Koenig W, Habib A et al. (1998) Activation of human aortic smooth-muscle cells is inhibited by PPAR $\alpha$ but not by PPARg activators. Nature 393: 790-793

9. Inoue I, Shino K, Noji S, Awata T, Katayama S (1998) Expression of peroxisome proliferator-activated receptor alpha (PPAR alpha) in primary cultures of human vascular endothelial cells. Biochem Biophys Res Commun 246: 370-374

10. Chinetti G, Griglio S, Antonucci M et al. (1998) Activation of proliferator-activated receptors alpha and gamma induces apoptosis of human monocyte-derived macrophages. J Biol Chem 273: 25573-25580

11. Frick MH, Syvanne M, Nieminen MS et al. (1997) Prevention of the angiographic progression of coronary and veingraft atherosclerosis by gemfibrozil after coronary bypass surgery in men with low levels of HDL cholesterol. Lopid Coronary Angiography Trial (LOCAT) Study Group. Circulation 96: 2137-2143

12. Oliver MF, Heady JA, Morris JN, Cooper J (1980) W. H. O. cooperative trial on primary prevention of ischaemic heart disease using clofibrate to lower serum cholesterol: mortality follow-up. Lancet ii:379-385

13. Frick MH, Elo O, Haapa K et al. (1987) Helsinki Heart Study: primary-prevention trial with gemfibrozil in middle-aged men with dyslipidemia. Safety of treatment, changes in risk factors, and incidence of coronary heart disease. N Engl J Med 317: 1237-1245

14. Betteridge DJ (1996) Lipids and atherogenesis in diabetes mellitus. Atherosclerosis 124[Suppl]:S43-S47

15. Stamler J, Vaccaro O, Neaton JD, Wentworth D (1993) Diabetes, other risk factors, and 12-yr cardiovascular mortality for men screened in the Multiple Risk Factor Intervention Trial. Diabetes Care 16: 434-444

16. Elkeles RS, Diamond JR, Poulter C et al. (1998) Cardiovascular Outcomes in Type 2 Diabetes. A double-blind pla- 
cebo-controlled study of bezafibrate: the St. Mary's, Ealing, Northwick Park Diabetes Cardiovascular Disease Prevention (SENDCAP) Study. Diabetes Care 21: 641-648

17. Lee SS, Pineau T, Drago J et al. (1995) Targeted disruption of the alpha isoform of the peroxisome proliferator-activated receptor gene in mice results in abolishment of the pleiotropic effects of peroxisome proliferators. Mol Cell Biol 15: 3012-3022

18. Peters JM, Hennuyer N, Staels B et al. (1997) Alterations in lipoprotein metabolism in peroxisome proliferator-activated receptor alpha-deficient mice. J Biol Chem 272: 27307-27312

19. Costet P, Legendre C, More J, Edgar A, Galtier P, Pineau T (1998) Peroxisome proliferator-activated receptor alphaisoform deficiency leads to progressive dyslipidemia with sexually dimorphic obesity and steatosis. J Biol Chem 273: 29577-29585

20. Kroetz DL, Yook P, Costet P, Bianchi P, Pineau T (1998) Peroxisome proliferator-activated receptor alpha controls the hepatic CYP4A induction response to starvation and diabetes. J Biol Chem 273: 31581-31589

21. Djouadi F, Weinheimer CJ, Saffitz JE et al. (1998) A gender-related defect in lipid metabolism and glucose homeostasis in peroxisome proliferator-activated receptor alphadeficient mice. J Clin Invest 102: 1083-1091

22. Skronowski R, Hollenbeck CB, Varasteh CB, Chen Y, Reaven GM (1991) Regulation of non-esterified fatty acid and glycerol concentration by insulin in normal individuals and patients with type 2 diabetes. Diabet Med 8: 330-333

23. Miller GJ, Bauer KA, Barzegar S, Cooper JA, Rosenberg RD (1996) Increased activation of the haemostatic system in men at high risk of fatal coronary heart disease. Thromb Haemost 75: 767-771

24. Gudnason V, Mak YT, Betteridge J, McCarthy SN, Humphries S (1993) Use of the single-strand conformational polymorphism method to detect recurrent and novel mutations in the low-density lipoprotein receptor gene in patients with familial hypercholesterolaemia: detection of a novel mutation Asp200 $\rightarrow$ Gly. Clin Investig 71: 331-337

25. Day IN, Humphries SE (1994) Electrophoresis for genotyping: microtiter array diagonal gel electrophoresis on horizontal polyacrylamide gels, hydrolink, or agarose. Anal Biochem 222: 389-395

26. Vu Dac N, Schoonjans K, Kosykh V et al. (1995) Fibrates increase human apolipoprotein A-II expression through activation of the peroxisome proliferator-activated receptor. J Clin Invest 96: 741-750

27. Sher T, Yi HF, McBride OW, Gonzalez FJ (1993) cDNA cloning, chromosomal mapping, and functional characterization of the human peroxisome proliferator activated receptor. Biochemistry 32: 5598-5604

28. Mukherjee R, Jow L, Noonan D, McDonnell DP (1994) Human and rat peroxisome proliferator activated receptors (PPARs) demonstrate similar tissue distribution but different responsiveness to PPAR activators. J Steroid Biochem Mol Biol 51: 157-166

29. Gearing KL, Crickmore A, Gustafsson JA (1994) Structure of the mouse peroxisome proliferator activated receptor alpha gene. Biochem Biophys Res Commun 199: 255-263

30. Steineger HH, Sorensen HN, Tugwood JD, Skrede S, Spydevold O, Gautvik KM (1994) Dexamethasone and insulin demonstrate marked and opposite regulation of the steady-state mRNA level of the peroxisomal proliferator-acti- vated receptor (PPAR) in hepatic cells. Hormonal modulation of fatty-acid-induced transcription. Eur J Biochem 225: 967-974

31. Shalev A, Siegrist Kaiser CA, Yen PM et al. (1996) The peroxisome proliferator-activated receptor alpha is a phosphoprotein: regulation by insulin. Endocrinology 137: 4499-4502

32. Staels B, Vu Dac N, Kosykh VA et al. (1995) Fibrates downregulate apolipoprotein C-III expression independent of induction of peroxisomal acyl coenzyme A oxidase. A potential mechanism for the hypolipidemic action of fibrates. J Clin Invest 95: 705-712

33. Vu Dac N, Schoonjans K, Laine B, Fruchart JC, Auwerx J, Staels B (1994) Negative regulation of the human apolipoprotein A-I promoter by fibrates can be attenuated by the interaction of the peroxisome proliferator-activated receptor with its response element. J Biol Chem 269: 31012-31018

34. Berthou L, Duverger N, Emmanuel F et al. (1996) Opposite regulation of human versus mouse apolipoprotein A-I by fibrates in human apolipoprotein A-I transgenic mice. J Clin Invest 97: 2408-2416

35. Staels B, Auwerx J (1998) Regulation of apo A-I gene expression by fibrates. Atherosclerosis 137[Suppl]:S19-S23

36. Vu Dac N, Chopin Delannoy S, Gervois P et al. (1998) The nuclear receptors peroxisome proliferator-activated receptor alpha and Rev-erbalpha mediate the species-specific regulation of apolipoprotein A-I expression by fibrates. J Biol Chem 273: 25713-25720

37. Garg A, Grundy S (1990) Management of dyslipidemia in NIDDM. Diabetes Care 13: 153-169

38. Jeck T, Riesen WF, Keller U (1997) Comparison of bezafibrate and simvastatin in the treatment of dyslipidaemia in patients with NIDDM. Diabet Med 14: 564-570

39. Laakso M, Lehto S, Penttila I, Pyorala K (1993) Lipids and lipoproteins predicting coronary heart disease mortality and morbidity in patients with non-insulin-dependent diabetes. Circulation 88: 1421-1430

40. Lehto S, Ronnemaa T, Haffner SM, Pyorala K, Kallio V, Laakso M (1997) Dyslipidemia and hyperglycemia predict coronary heart disease events in middle-aged patients with NIDDM. Diabetes 48: 1354-1359

41. Florkowski CM, Scott RS, Moir CL, Graham PJ (1998) Lipid but not glycaemic parameters predict total mortality from type 2 diabetes mellitus in Canterbury, New Zealand. Diabet Med 15: 386-392

42. Pyorala K, Pedersen TR, Kjekshus J, Faergeman O, Olsson AG, Thorgeirsson G (1997) Cholesterol lowering with simvastatin improves prognosis of diabetic patients with coronary heart disease. A subgroup analysis of the Scandinavian Simvastatin Survival Study (4S) [published erratum appears in Diabetes Care 1997 Jun; 20: 1048] Diabetes Care 20: 614-620

43. Hsu MH, Palmer CN, Song W, Griffin KJ, Johnson EF (1998) A carboxyl-terminal extension of the zinc finger domain contributes to the specificity and polarity of peroxisome proliferator-activated receptor DNA binding. J Biol Chem 273: 27988-27997

44. Juge-Aubry C, Pernin A, Favez T et al. (1997) DNA binding properties of peroxisome proliferator-activated receptor subtypes on various natural peroxisome proliferator response elements. Importance of the 5 '-flanking region. J Biol Chem 272: 25252-25259 